\title{
Air curtain as a barrier against pollutants in cultural heritage: a case study
}

\author{
L. de Santoli, F. Cumo \& M. Mariotti \\ Centro Interdisciplinare CITERA, Università "La Sapienza" Roma, Italy
}

\begin{abstract}
Every year millions of people visit the works of art placed in museums, which aren't the safest place to protect cultural heritages from air pollutants.

The use of air curtains may often represent a protection for the cultural heritage without operating on the material of the objects, and without limiting the perception of the work of art. The aim of this work consists of the characterisation of this device, which is widely used in industry, but not yet frequently adopted in the field of conservation of works of art. As a matter of fact, the employment of air curtains to segregate pollutant diffusion near the sources of fire prevention is actually more and more diffused in industry buildings. Their success is due to the peculiarity to separate zones without fixed barriers which would interfere with people and equipment. The application of air flows in museums deals with the problem of separating visitors and objects in order to protect the latter from pollutants.

When a decontamination treatment of the visitors is provided, by means of an air curtain system that is able to remove most of the potentially dangerous pollutants from people as they enter, an "indirect protection method" is defined. An ongoing research of the latter is presently studied in the Museum of the Rocca di Vignola (Modena) to remove pollutants from visitors of the fresco painted chapel.

In the present paper some CFD simulations performed with FLUENT ${ }^{\circledR}$ are compared with the experimental measures realized after the first utilization of the air curtain outside the fresco chapel of "Uguccione Contrari" in Vignola.

As a preliminary result it is possible to underline the good accordance between simulation and experimental results so that it is possible to be confident in using CFD simulation code as a design tool for dynamic barriers against pollutants in cultural heritage.
\end{abstract}




\section{Introduction}

The Rocca di Vignola [2] is perhaps the most important and beloved symbol of geographical and cultural identity of the Panaro Valley, going back to when the stronghold was a bastion and a centre of aggregate economy for its inhabitants, to its subsequent transformation into an elegant Renaissance castle, a pole of attraction for artists, musicians, scholars and politicians.

The Rocca was built as a defensive-offensive structure and maintained those features during the domination of the Grassoni family in the 14th century and the Contrary dynasty in the following two hundred years. After the extinction of this dynasty, the Rocca was purchased by the Boncompagni family in 1577 until 1965 when the Town Hall and the Cassa di Risparmio di Vignola purchased the estate. Nowadays the Rocca accommodates an average of 200 events every year and this prestigious host of important cultural heritages is visited by thousands of visitors (more than 50,000 every year) and is a significant tourist attraction for the provinces of Modena, Reggio Emilia and Bologna.

The most significative cultural heritage of the site is the precious series of late Gothic frescoes adorning the Rocca chapel, portraying images and characters from Christ's stories which are attributed to the "Master of Vignola" in a period around 1430. Three of the main frescoes of the Rocca chapel are shown in Figure 1 .
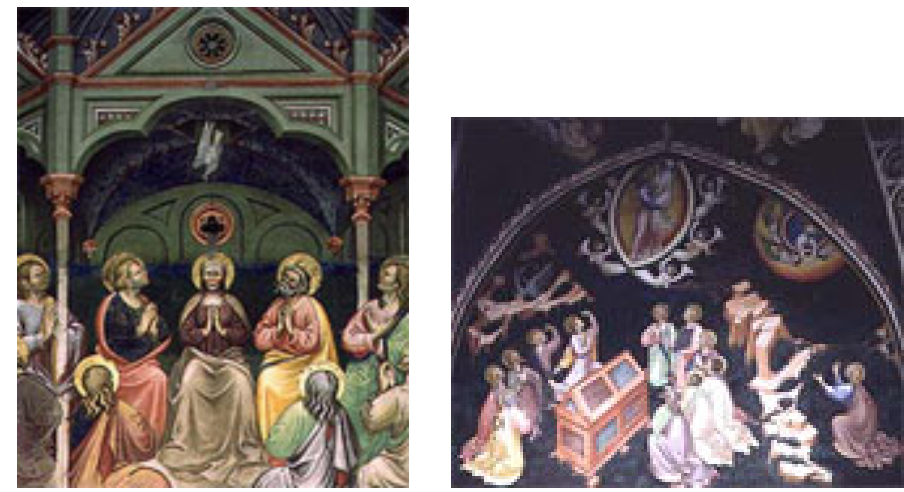

Figure 1: $\quad$ Images of the chapel frescoes.

\section{Technical intervention}

The aim of the intervention is the reduction of the airborne pollutants inside the chapel due to the high flow of visitors coming into a small area where it is impossible, both for artistic and technical reasons, to install an HVAC system.

All those pollutants may stick on the fresco surfaces so as to compromise the original composition, causing a frequent need for restoration intervention. In the Vatican Museums nowadays (with million of visitors every year) the restoration intervention frequency on the paintings is about 25 years, while in the past centuries it was in the order of one hundred years. 
In order to minimize the presence of mechanical equipment the following solution has been pointed out as reported in figure 2, based on the use of an air curtain in the area immediately outside the chapel area, mounted on the entrance door.

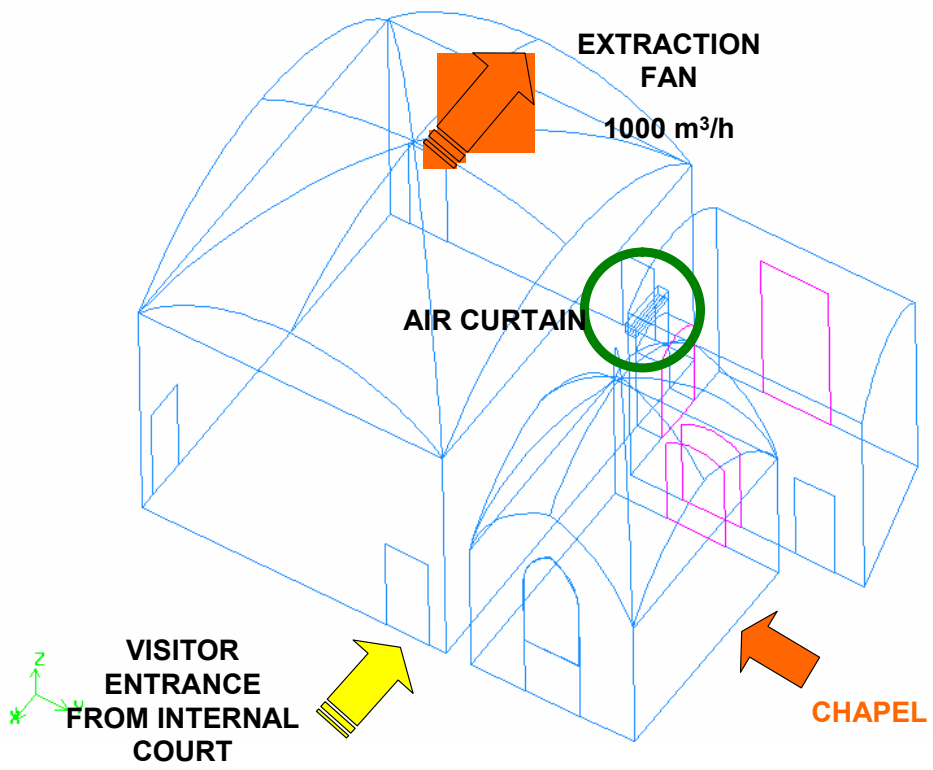

Figure 2: Scheme of technical intervention.

This air curtain, having an air velocity of about $4-5 \mathrm{~m} / \mathrm{s}$, will be utilized to remove a great part of the dust, hairs, pollen and other biological residuals that usually stay on visitors' clothes

Moreover, the installation of an air extractor of about $1000 \mathrm{mc} / \mathrm{h}$ in the hall outside the antechapel has been realized, in order to capture the airborne pollutants removed by the air curtain. The main function of this fan is to depressurize the area avoiding the entrance of pollutants into the antechapel and into the chapel area.

\section{CFD simulation}

In order to verify the efficiency of the proposed solution in terms of percentage of airborne pollutants removed from the chapel area a simulation has been performed using simulation code Fluent ${ }^{\circledR}$; in the first step the whole area has been subdivided into a mesh as reported in figure 3 with particular accuracy for the areas surrounding the air curtain and the chapel window, and the small room where the extraction fan is installed. 


\section{SIMULATION MODEL mesh 230.000 nodes}

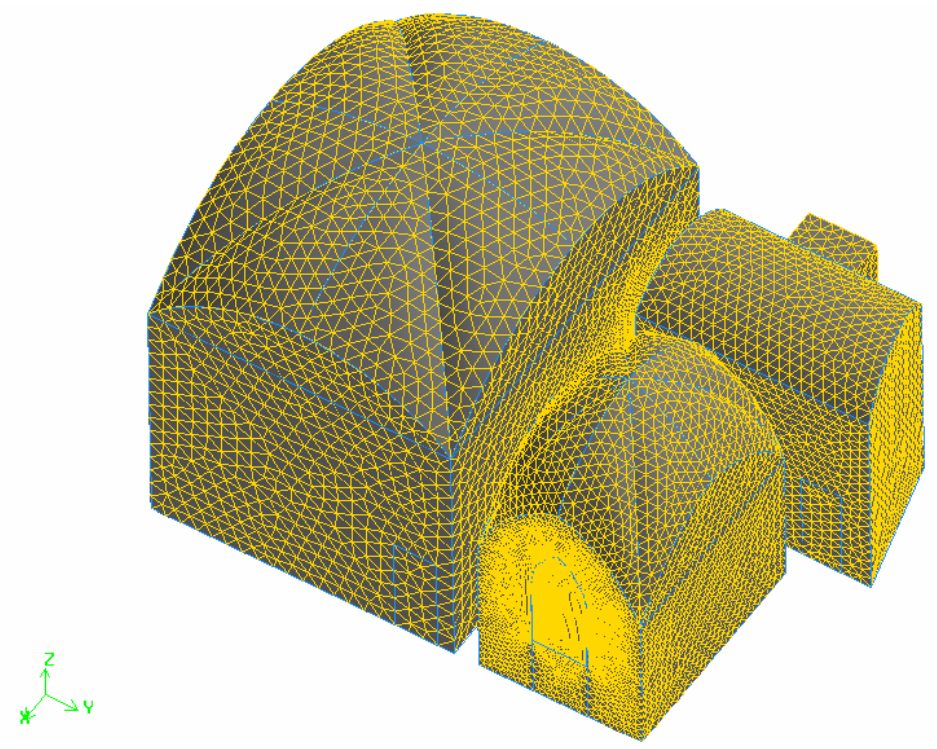

Figure 3: $\quad$ Simulation model of the whole area.

The results of the simulation, performed with an air velocity in the outlet section of the air curtain of $4 \mathrm{~m} / \mathrm{s}$ and an extraction flow rate of $1000 \mathrm{mc} / \mathrm{h}$ located in a small room of the entrance area, are reported in figures 4 and 5 [3].

In figure 4 it is possible to see that the main air flow direction is from the air curtain to the extraction fan, with a mean air velocity of about $0.15 \mathrm{~m} / \mathrm{s}$; as a consequence, the main part of the airborne pollutants removed from the visitors clothes by the action of the air curtain moves from the door to the extraction fan area, avoiding contamination of the antechapel. In fact it is possible to underline that only a few air flow lines (about 25\%) move across the separation area towards the controlled area carrying particulate and other airborne pollutants around the fresco chapel; the above mentioned situation leads to an evaluation of about more than $70 \%$ of the pollutants carried by the visitors removed in the entrance room, just outside the critical chapel zone.

The removal effectiveness of the air curtain-extraction fan system is extremely important for the preservation of the fresco in the chapel; in fact as reported in figure 5, the antechapel room has a higher pressure than the chapel, due to the presence of a big and not sealed window in the chapel wall. As a consequence of the air movements reported, nearly all the airborne pollutants passing through the separation area come in the chapel with a high risk of deterioration of the fresco paints. 

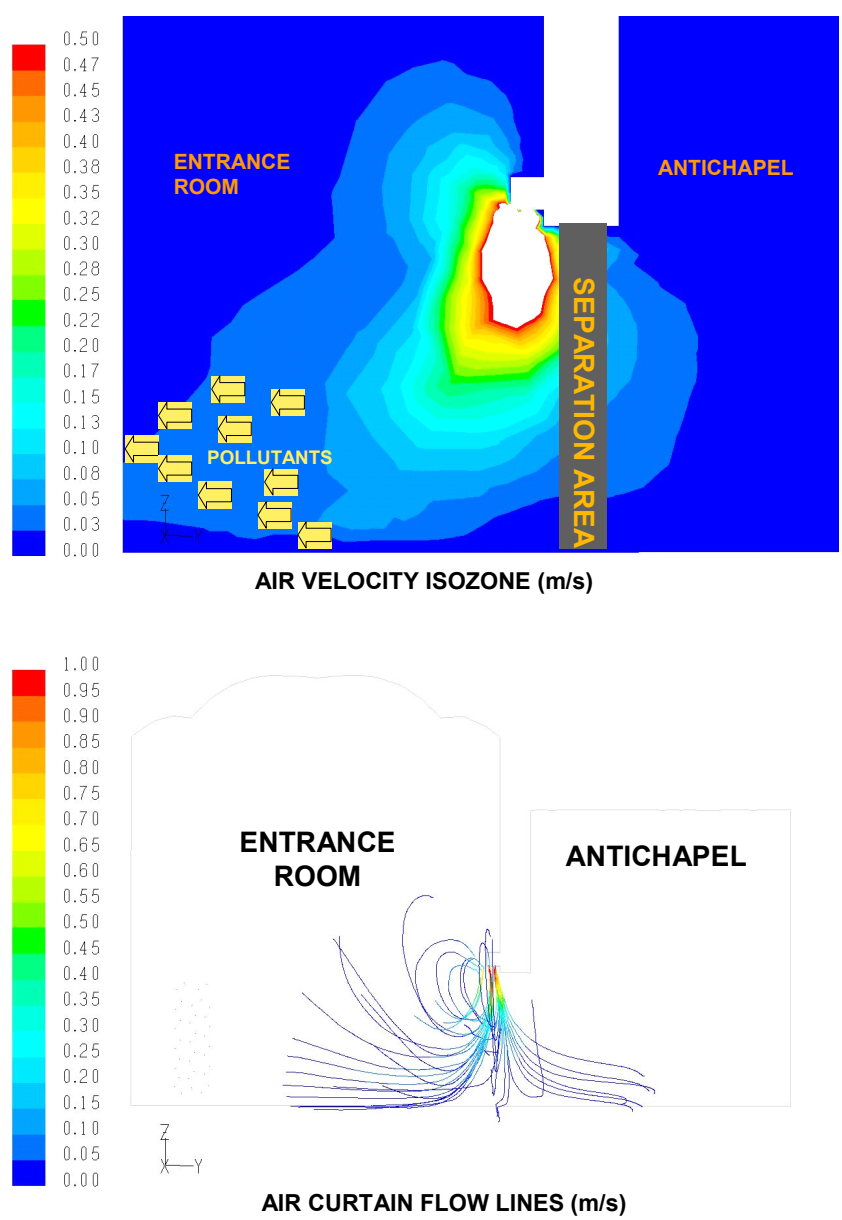

Figure 4: $\quad$ Air velocity and air flow in a cross section on the air curtain.

\section{The experimental monitoring campaign}

In order to validate the simulation results, an on-line monitoring of temperature, relative humidity, $\mathrm{CO}, \mathrm{CO}_{2}$ and fine particulate $\left(\mathrm{PM}_{10}\right.$ and $\left.\mathrm{PM}_{2.5}\right)$ has been performed for a two-day period in the three involved rooms of the area (entrance area, antechapel and chapel).

For thermal-hygrometric measures and $\mathrm{CO}$ and $\mathrm{CO}_{2}$ detection an LSI BABUC-M has been utilized connected with a hot-wire velocity air probe in order to evaluate air change rate. Fine particulate $\mathrm{PM}_{10}$ has been detected with a Dust Track Mounter TSI mod. 8520 in conformity with technical requirements of the V annex of the Italian Environmental Ministry Decree 23/11/1994. 


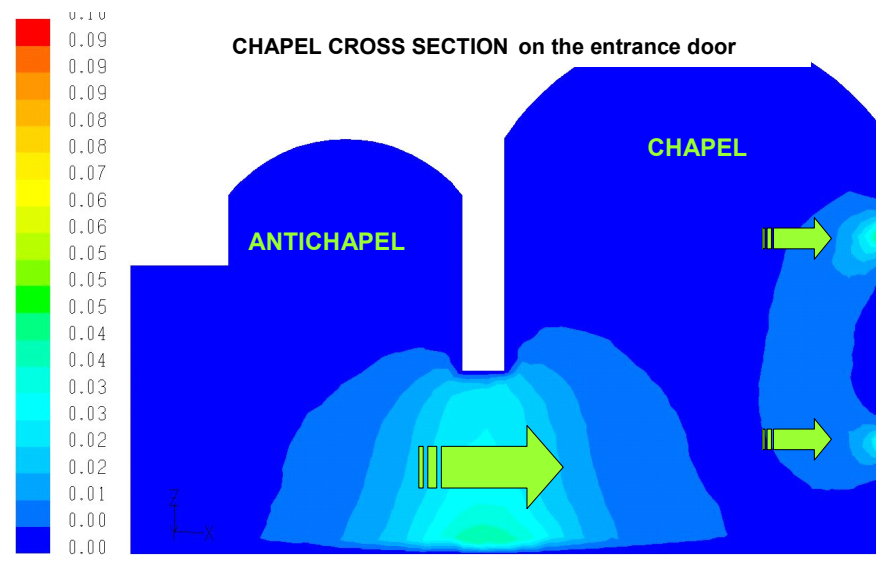

AIR VELOCITY ISOZONE (m/s)
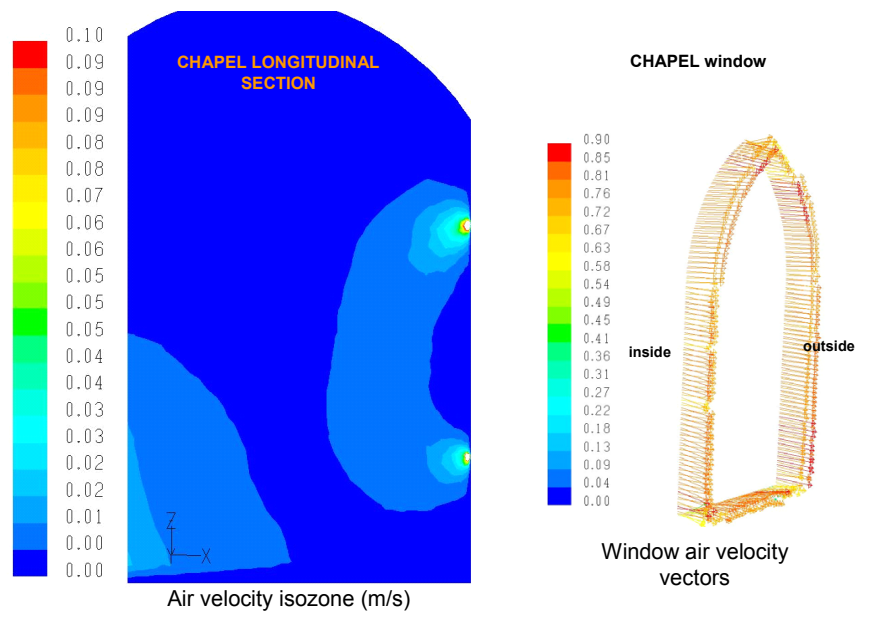

Figure 5: Air velocity and air flow in a cross and longitudinal section on the chapel area.

Ultra-fine particulate $\mathrm{PM}_{2.5}$ has been detected with $\mathrm{PM}_{2.5} \mathrm{EN}$ LVS equipment (see figure 1), according to the En 12341 regulation [4, 5] and Italian Law Decree $n^{\circ} 6002 / 04 / 2002$; the suction air flow rate is equal to 38 litres/minute and the monitoring period range is between 12 and 24 hours.

In each room all the described parameters have been monitored always when the installed systems was switched on.

The mean data coming from the two-day monitoring campaign inside the described area are reported in table 1 . The measurements have been performed with about 50 visitors/h passing through the air curtain and staying in the chapel for five minutes in groups of 5 . 
For a better comprehension of the data, in bold are reported those values (coming from the mean of the results of the three monitorings) exceeding the comfort and health limits deduced from the following Italian regulations:

$\mathrm{T}, \mathrm{UR}$
$\mathrm{CO}, \mathrm{CO}_{2}$
$\mathrm{PM}_{10}$
$\mathrm{PM}_{2,5}$

Technical Regulation UNI 10339

Italian Ministry Decree n. 159 25/11/1994

Italian Ministry Decree n. 159 25/11/1994

Environmental Ministry Decree n. 60 02/04/2002

Table 1: Monitoring results.

\begin{tabular}{|c|c|c|c|c|c|}
\hline AREAS & $\begin{array}{l}\mathrm{T}\left[{ }^{\circ} \mathbf{C}\right] / / \\
\mathbf{U R}[\%]\end{array}$ & $\begin{array}{c}\mathbf{P M}_{10} \\
{\left[\mu \mathrm{g} / \mathbf{m}^{3}\right]}\end{array}$ & $\begin{array}{l}\mathrm{PM}_{2.5} \\
{\left[\mu \mathrm{g} / \mathrm{m}^{3}\right]}\end{array}$ & $\begin{array}{c}\mathrm{CO} \\
{[\mathrm{ppm}]}\end{array}$ & $\begin{array}{c}\mathrm{CO}_{2} \\
{[\mathrm{ppm}]}\end{array}$ \\
\hline LIMITS & & 150 & 50 & 8 & $650-700$ \\
\hline \begin{tabular}{|l|} 
Lounge with \\
extraction fan
\end{tabular} & $21.2 / 54.6$ & 115 & 41 & 0 & 695 \\
\hline Antechapel & $21.4 / 60.2$ & 76 & 30 & 0 & 815 \\
\hline Chapel & $21.4 / 57$ & 74 & 30 & 0 & 832 \\
\hline $\begin{array}{l}\text { External } \\
\text { environment }\end{array}$ & $19.7 / 53$ & 60 & 25 & 0 & 640 \\
\hline
\end{tabular}

Using $\mathrm{PM}_{10}$ concentration as a performance indicator of the system efficiency, is it possible to underline that $55 \mu \mathrm{g} / \mathrm{m}^{3}$ of particulates, exceeding the external value of $60 \mu \mathrm{g} / \mathrm{m}^{3}$, are introduced by the visitors in the first room before the air curtain; only $16 \mu \mathrm{g} / \mathrm{m}^{3}$ pass through the air curtain in the antechapel room with an abatement factor of about $71 \%$, while almost $85 \%$ of this $\mathrm{PM}_{10}(14$ $\mu \mathrm{g} / \mathrm{m}^{3}$ ) pass from the antechapel into the frescoes chapel.

\section{Conclusions and further developments}

The results of the monitoring data are absolutely in good accordance with simulation outputs; in fact both represent an efficiency of the system (air curtain-extraction fan) varying from 70 to $75 \%$.

It is important to underline that the installed equipment is able to reduce the risk for fresco painting caused by airborne pollutants introduced by visitors, while those coming from outside by the windows and the entrance door still remain.

The research shows that CFD codes used for mechanical equipment in a confined environment are a very important design tool in order to optimize all the system parameters.

A further monitoring campaign will be performed in the next few months in order to confirm this preliminary data with a deeper analysis of the presence of extra-fine particulates $\mathrm{PM}_{2.5}$ and $\mathrm{PM}_{1}$. 


\section{Acknowledgements}

The authors wish to thank the Cassa di Risparmio di Vignola Foundation and arch. Vincenzo Vandelli for their support in this research.

\section{References}

[1] De Santoli L. Mariotti M. Study to protect Michelangelo's David from indoor air pollutants. AICARR Conference 20 September 2005.

[2] Fondazione Cassa di Risparmio di Vignola The history of the Rocca di Vignola. 2003,.

[3] Gugliermetti F. Santarpia L. A phenomenological approach to the performance of shutter type air curtains Air Pollution 27-29 July, San Francisco 1999.

[4] De Santoli L., Fracastoro G., (1998) La qualità dell'aria negli ambienti interni. Soluzioni e strategie. (in Italian). Collana AICARR.

[5] Chang LT, Suh HH, Wolfson JM et al. Laboratory and field evaluation of measurement methods for one-hour exposure to O3, $\mathrm{PM}_{2.5}$ and CO. J Air \& Waste Manag Assoc 2001; 51: 1414-22. 